Supporting Information for

\title{
Silver Nanoparticles Alter Soil Microbial \\ Community Compositions and Metabolite Profiles in Unplanted and Cucumber-planted Soil
}

Huiling Zhang§, Min Huang§, Wenhui Zhang§, Jorge L. Gardea-Torresdey $\zeta$, Jason C. Whiteף, Rong Ji ${ }^{\&}$, Lijuan Zhao§*

§State Key Laboratory of Pollution Control and Resource Reuse, School of Environment, Nanjing University, Nanjing 210023, China

¿ Department of Chemistry and Biochemistry, The University of Texas at El Paso, 500

West University Avenue, El Paso, Texas 79968, United States

'Department of Analytical Chemistry, The Connecticut Agricultural Experiment

Station (CAES), New Haven, Connecticut 06504, United States

${ }^{*}$ Corresponding author. Tel: +86 025-8968 0581; fax: +86 025-8968 0581.

Email address: ji@nju.edu.cn; ljzhao@nju.edu.cn 
Page S3-S6 Supporting Information for Method (Soil Chemical Analysis, photosynthetic pigments determination, total phenolic content and lipid peroxidation assay, GC-MS based metabolomics)

Page S7 Table S1

Page S8-14 Figure S1 to S7. 


\section{Supporting Information for Method}

Soil Chemical Analysis. Soil pH, dissolved organic carbon and extractable macro/micro element content were determined according to the protocol of Houba et al. ${ }^{1}$ Briefly, 3 g soil mixed with $30 \mathrm{~mL} 0.01 \mathrm{M} \mathrm{CaCl}_{2}$ was shaken for two hours at 200 $\mathrm{rpm}$ at $20^{\circ} \mathrm{C}$. The $\mathrm{pH}$ of the suspension was then measured using a $\mathrm{pH}$ meter (MettlerToledo, Switzerland). After centrifugation at $10000 \mathrm{rpm}$ for $10 \mathrm{~min}$, the supernatant was collected and filtered through $0.45 \mu \mathrm{m}$. The dissolved organic carbon was measured by VarioTOC Analyzer (Elementar, Germany) with Potassium phthalate monobasic (KHP) for calibration. The water extractable element content (K, $\mathrm{Ca}, \mathrm{Mg}, \mathrm{Si}, \mathrm{Mn}, \mathrm{Al}$, $\mathrm{Cu}, \mathrm{Ag}, \mathrm{Ti}, \mathrm{Cd}$ ) was determined by inductively coupled plasma optical emission spectroscopy (ICP-OES, Optima 8300, Perkin Elmer, USA) and ICP- mass spectrometry (MS) (NexION-300, PerkinElmer, USA). An ICP QC standard solution (NSI Solution Incorporated, USA) were used for calibration and quantitation.

Photosynthetic Pigments Determination. One hundred $\mathrm{mg}$ fresh leaves were extracted with $5 \mathrm{~mL} 80 \%$ acetone and ethanol (v:v=1:1) for $12 \mathrm{~h}$. After centrifugation at $4000 \mathrm{rpm}$ for $10 \mathrm{~min}$, the absorbance of chlorophyll a, chlorophyll $\mathrm{b}$ and carotenoid at $663 \mathrm{~nm}, 645 \mathrm{~nm}$ and $470 \mathrm{~nm}$, respectively, in the supernatant were measured by microplate reader (Synergy H4 Hybrid Reader, Biotek, America).

Total Phenolic Content. Total phenolic content was determined based on the method of Singleton and Rossi. ${ }^{2}$ Briefly, the leaf powder was extracted with $80 \%$ acetone and ethanol (v:v=1:1). Then, $50 \mu \mathrm{L}$ extracts was mixed with $450 \mu \mathrm{L}$ water, followed by the addition of $250 \mathrm{~mL}$ Folin phenol reagent and $1.25 \mathrm{~mL} 20 \mathrm{~g} / \mathrm{L} \mathrm{Na}_{2} \mathrm{CO}_{3}$ solution. 
Absorbance at $750 \mathrm{~nm}$ was measured by microplate reader (Synergy H4 Hybrid Reader, Biotek, America) and the total phenolic content was expressed as mg Gallic acid equivalent $\mathrm{g}^{-1}$ of fresh weight.

Lipid Peroxidation Assay. Lipid peroxidation was determined according to the protocol of Jambunathan (2010). ${ }^{3}$ Lipid peroxidation was expressed as $\mu$ mol MDA equivalent $\mathrm{g}^{-1}$ of fresh weight. Briefly, $0.1 \mathrm{~g}$ of cucumber leaves was mixed with $4 \mathrm{~mL}$ of $0.1 \% \mathrm{TCA}$, followed by centrifugation at $10000 \mathrm{rpm}$ for $15 \mathrm{~min}$. One $\mathrm{mL}$ of the supernatant was mixed with $2 \mathrm{~mL}$ of $20 \% \mathrm{TCA}$ and $2 \mathrm{~mL}$ of $0.5 \% \mathrm{TBA}$; the mixture was then heated in a water bath at $95^{\circ} \mathrm{C}$ for $30 \mathrm{~min}$. After cooling, absorbance at 532 $\mathrm{nm}$ and $600 \mathrm{~nm}$ was measured with microplate reader (Synergy H4 Hybrid Reader, Biotek, America).

\section{GC-MS based Metabolomics.}

Soil Metabolite Extraction (Sample preparation). At harvest, a $1000 \mathrm{mg}$ soil sample from each treatment (pot) was sieved to $2 \mathrm{~mm}$ and then ground to a fine powder in liquid $\mathrm{N}_{2}$ and stored at $-80{ }^{\circ} \mathrm{C}$ for later extraction. One gram of soil was weighed and transferred to a $1.5-\mathrm{mL}$ Eppendorf tube, followed by the addition of $1 \mathrm{~mL}$ of methanol and water (1: $1=\mathrm{v}: \mathrm{v})$ and $20 \mu \mathrm{L}$ of 2-chloro-1-phenylalanine $(0.3 \mathrm{mg} / \mathrm{mL}$, dissolved in methanol as internal standard). The mixture was sonicated at $60 \mathrm{HZ}$ for $2 \mathrm{~min}$. The extraction was repeated three times and was centrifuged at $12000 \mathrm{rpm}$ for $10 \mathrm{~min}$ at $4{ }^{\circ} \mathrm{C}$. The supernatant was transferred to a 5-ml Eppendorf tube and freeze dried. The dried powder was resuspended in $400 \mathrm{uL}$ methanol: water (v: $\mathrm{v}=1: 1)$, vortexed for $60 \mathrm{~s}$ followed by sonication for 30s. The suspensions were centrifuged at $12000 \mathrm{rpm}$ for 10 
$\min$ at $4{ }^{\circ} \mathrm{C}$.

A QC sample was prepared by mixing aliquots of the all samples to obtain a pooled sample. An aliquot of the $300 \mu \mathrm{L}$ supernatant was transferred to a glass sampling vial for vacuum-drying at room temperature. Eighty $\mu \mathrm{L}$ of $15 \mathrm{mg} / \mathrm{mL}$ methoxylamine hydrochloride in pyridine was subsequently added. The resulting mixture was vortexed vigorously for $2 \mathrm{~min}$ and incubated at $37^{\circ} \mathrm{C}$ for $90 \mathrm{~min}$. Eighty $\mu \mathrm{L}$ of BSTFA (with $1 \%$ TMCS) and $20 \mu \mathrm{L}$ n-hexane was added to the mixture, which was vortexed vigorously for $2 \mathrm{~min}$ and then derivatized at $70^{\circ} \mathrm{C}$ for $60 \mathrm{~min}$. The samples were placed at ambient temperature for $30 \mathrm{~min}$ before GC-MS analysis.

GC-MS Analysis. The derivatized sample extracts were analyzed on an Agilent 7890B gas chromatography system coupled to an Agilent 5977A mass selective detector (single quadrupole) (Agilent Technologies Inc., CA, USA). The column employed was a DB-5MS fused-silica capillary column $(30 \mathrm{~m} \times 0.25 \mathrm{~mm} \times 0.25 \mu \mathrm{m}$; Agilent J \& W Scientific, Folsom, CA, USA Agilent Technologies, Santa Clara, CA). Helium ( $>99.999 \%$ ) was used as the carrier gas at a constant flow rate of $1.0 \mathrm{~mL} / \mathrm{min}$ through the column. The initial oven temperature was $60^{\circ} \mathrm{C}$, ramped to $125^{\circ} \mathrm{C}$ at a rate of $8{ }^{\circ} \mathrm{C} / \mathrm{min}$, to $210^{\circ} \mathrm{C}$ at a rate of $4{ }^{\circ} \mathrm{C} / \mathrm{min}$, to $270{ }^{\circ} \mathrm{C}$ at a rate of $5^{\circ} \mathrm{C} / \mathrm{min}$, to $305^{\circ} \mathrm{C}$ at a rate of $10{ }^{\circ} \mathrm{C} / \mathrm{min}$, and finally, held at $305^{\circ} \mathrm{C}$ for $3 \mathrm{~min}$. The injection volume was $1 \mu \mathrm{L}$ with the injector temperature $260^{\circ} \mathrm{C}$ in splitless mode. The temperature of MS quadrupole and ion source (electron ionisation) was set to 150 and $230{ }^{\circ} \mathrm{C}$, respectively. The ionisation energy was $70 \mathrm{eV}$. Mass data was acquired in a full-scan mode (m/z 50500), and the solvent delay time was set to $5 \mathrm{~min}$. Quality control samples, which were 
prepared by applying small aliquots from each sample with L-2-Chlorophenylalanine as internal standard, were injected at regular intervals (every 10 samples) throughout the analytical run.

\section{Reference}

1. Houba, V. J. G.; Temminghoff, E. J. M.; Gaikhorst, G. A.; van Vark, W., Soil analysis procedures using $0.01 \mathrm{M}$ calcium chloride as extraction reagent. Communications in Soil Science and Plant Analysis 2008, 31, (9-10), 1299-1396.

2. Singleton, V. L.; Rossi, J. A., Colorimetry of Total Phenolics with Phosphomolybdic-Phosphotungstic Acid Reagents. American Journal of Enology and Viticulture 1965, 16, (3), 144-158.

3. Jambunathan, N., Determination and Detection of Reactive Oxygen Species (ROS), Lipid Peroxidation, and Electrolyte Leakage in Plants. In Plant Stress Tolerance: Methods and Protocols, Sunkar, R., Ed. Humana Press: Totowa, NJ, 2010; pp 291-297. 
Table S1. Soil background elemental analysis (mg/kg dry soil)

\begin{tabular}{ccccccc}
\hline $\mathrm{Al}$ & $\mathrm{Fe}$ & $\mathrm{Ca}$ & $\mathrm{K}$ & $\mathrm{Mg}$ & $\mathrm{Mn}$ & $\mathrm{Na}$ \\
\hline $21663 \pm 1014$ & $15407 \pm 973$ & $4291 \pm 264$ & $3879 \pm 164$ & $3365 \pm 189$ & $276 \pm 31$ & $166 \pm 16$ \\
\hline $\mathrm{Ti}$ & $\mathrm{Cr}$ & $\mathrm{Zn}$ & $\mathrm{Ni}$ & $\mathrm{Pb}$ & $\mathrm{Cu}$ & $\mathrm{Mo}$ \\
\hline $1469 \pm 281$ & $31.1 \pm 5.0$ & $26.4 \pm 2.7$ & $21.5 \pm 1.6$ & $10.9 \pm 0.8$ & $16.1 \pm 1.5$ & $0.19 \pm 0.02$ \\
\hline
\end{tabular}




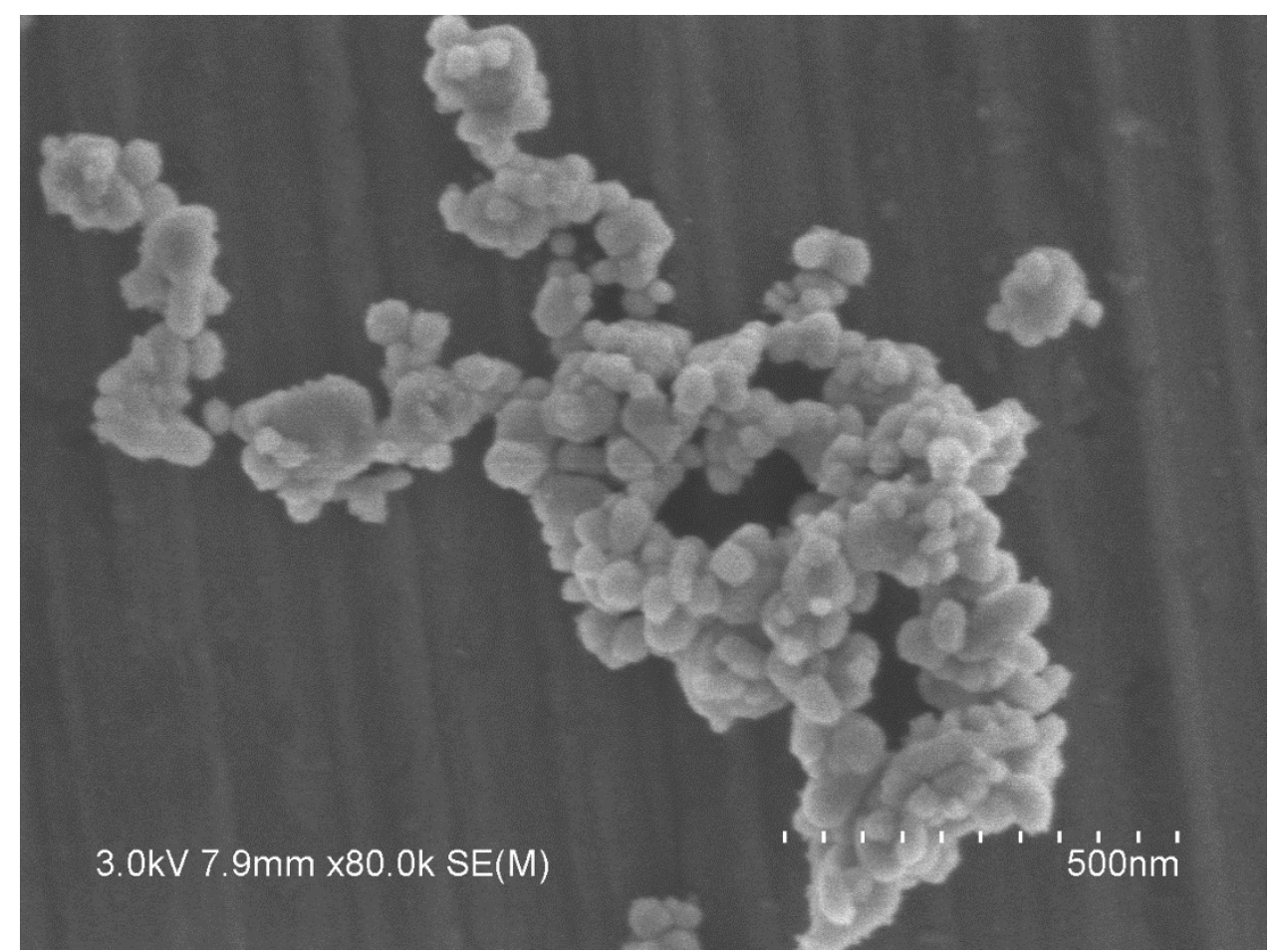

Figure S1. SEM image of silver nanoparticles 

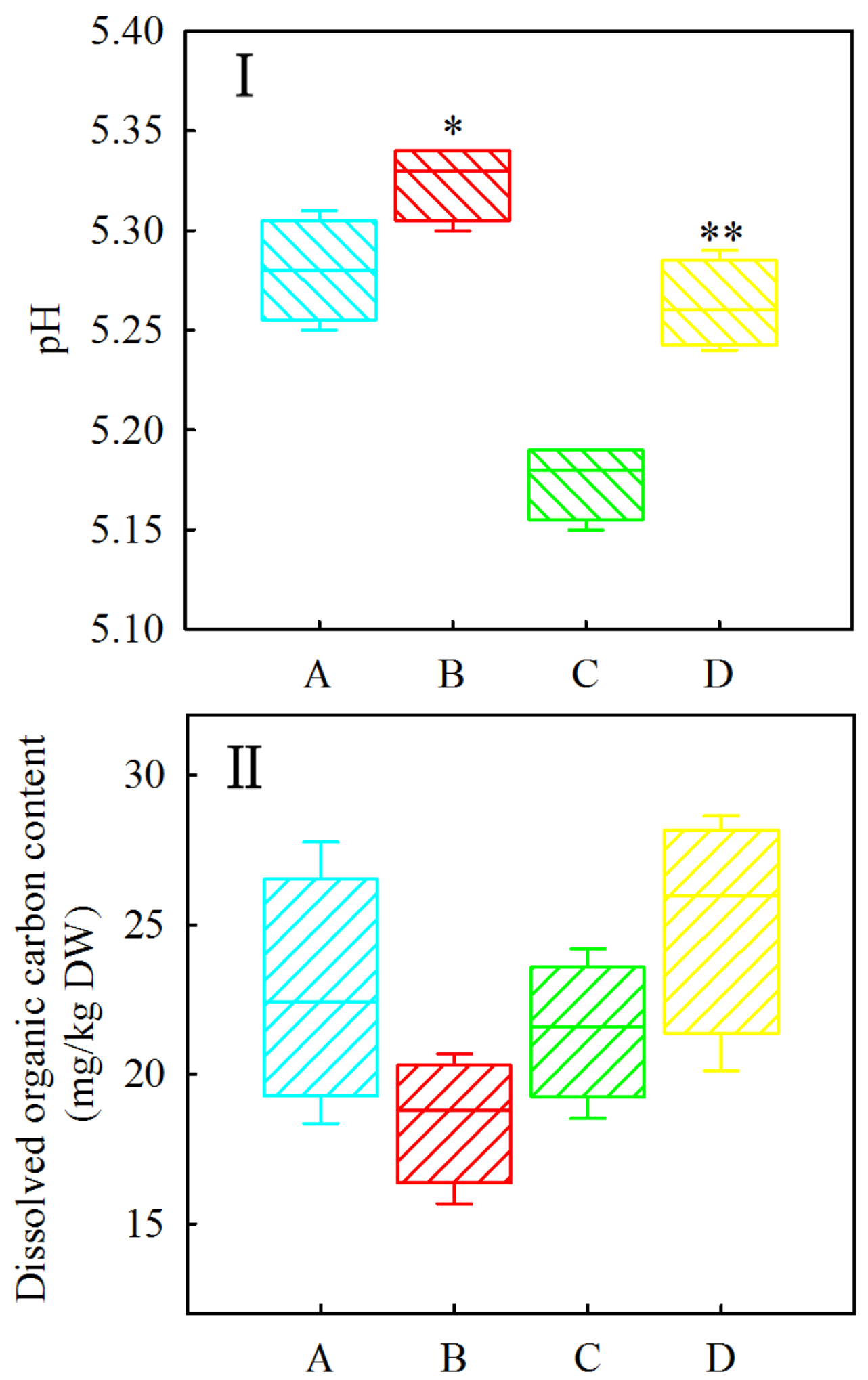

Figure S2. Soil pH (I) and dissolved organic carbon content (II). A: soil, B: soil+AgNPs, C: soil+plant, D: soil+plant+AgNPs. The data were represented by means \pm SD by four replicates. * represent the significance is below $0.05, * *$ represent the significance is below 0.01 . 


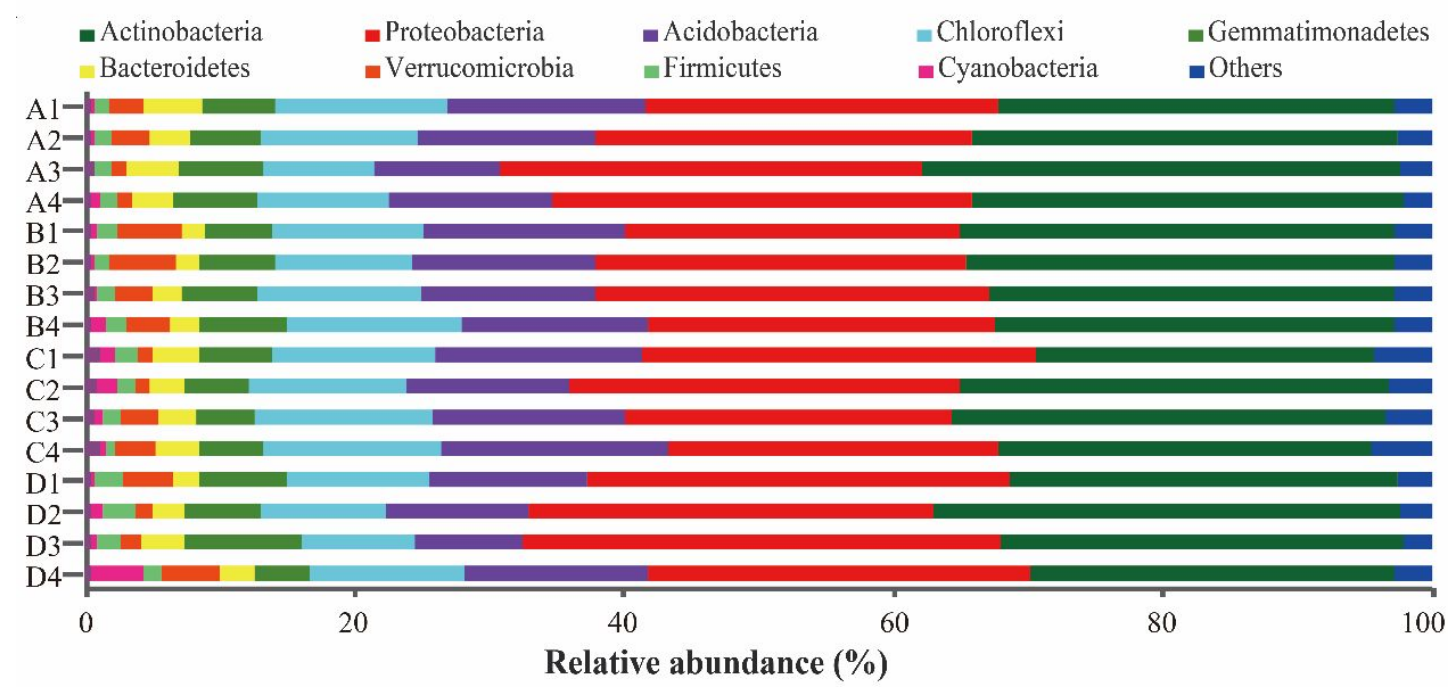

Figure S3. Bacterial community composition with the relative abundance of the bacterial phyla. A: soil, B: soil+AgNPs, C: soil+plant, D: soil+plant+AgNPs. 


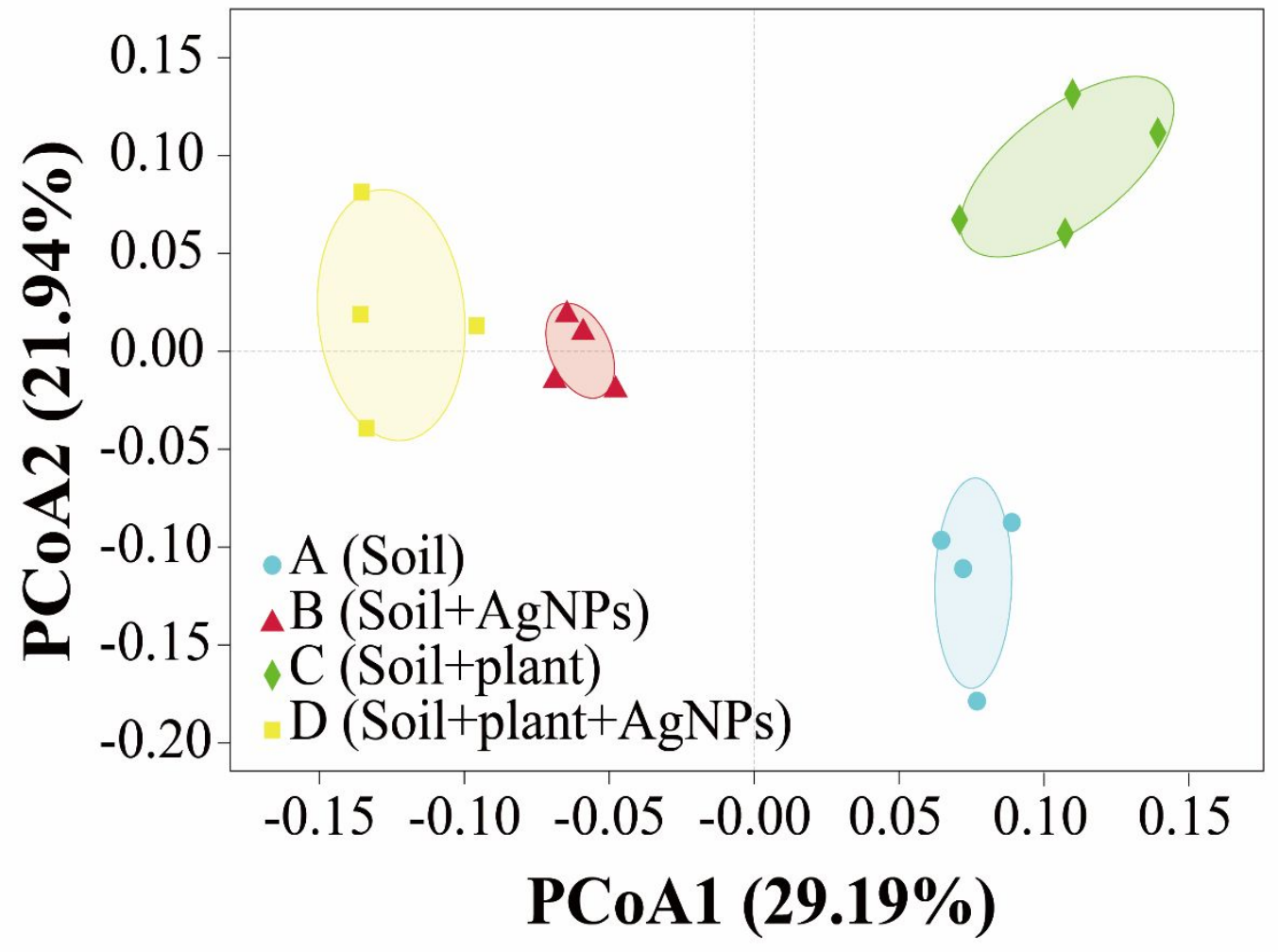

Figure S4. Bray-Curtis distance of bacterial communities. A: soil, B: soil+AgNPs, C: soil+plant, D: soil+plant+AgNPs. 


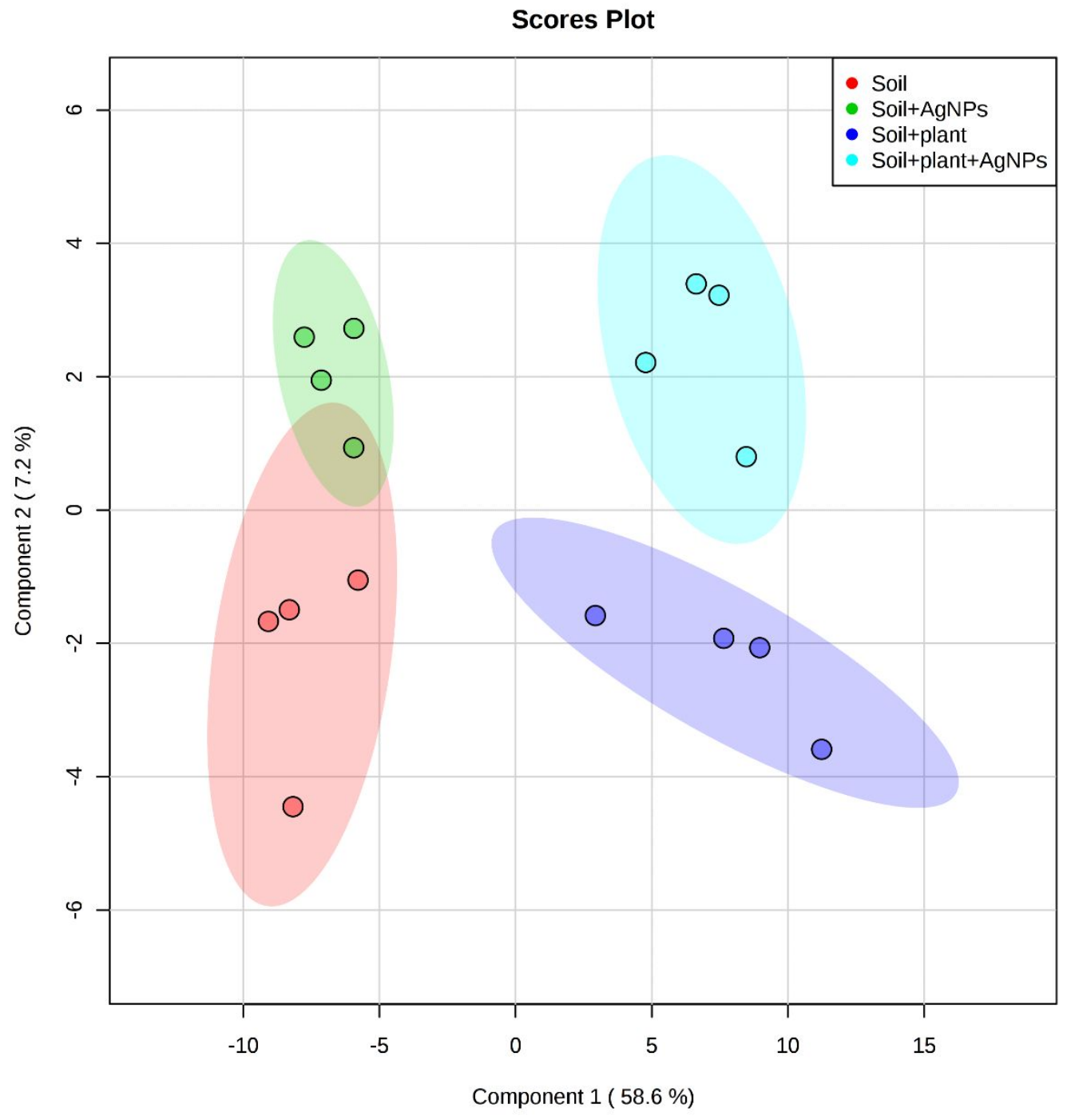

Figure S5. Partial least-squares discriminant (PLS-DA) scores plot of metabolites in soil. AgNPs at $100 \mathrm{mg} / \mathrm{kg}$ were amended in soil in absence or in presence of cucumber plants for 60 days. 


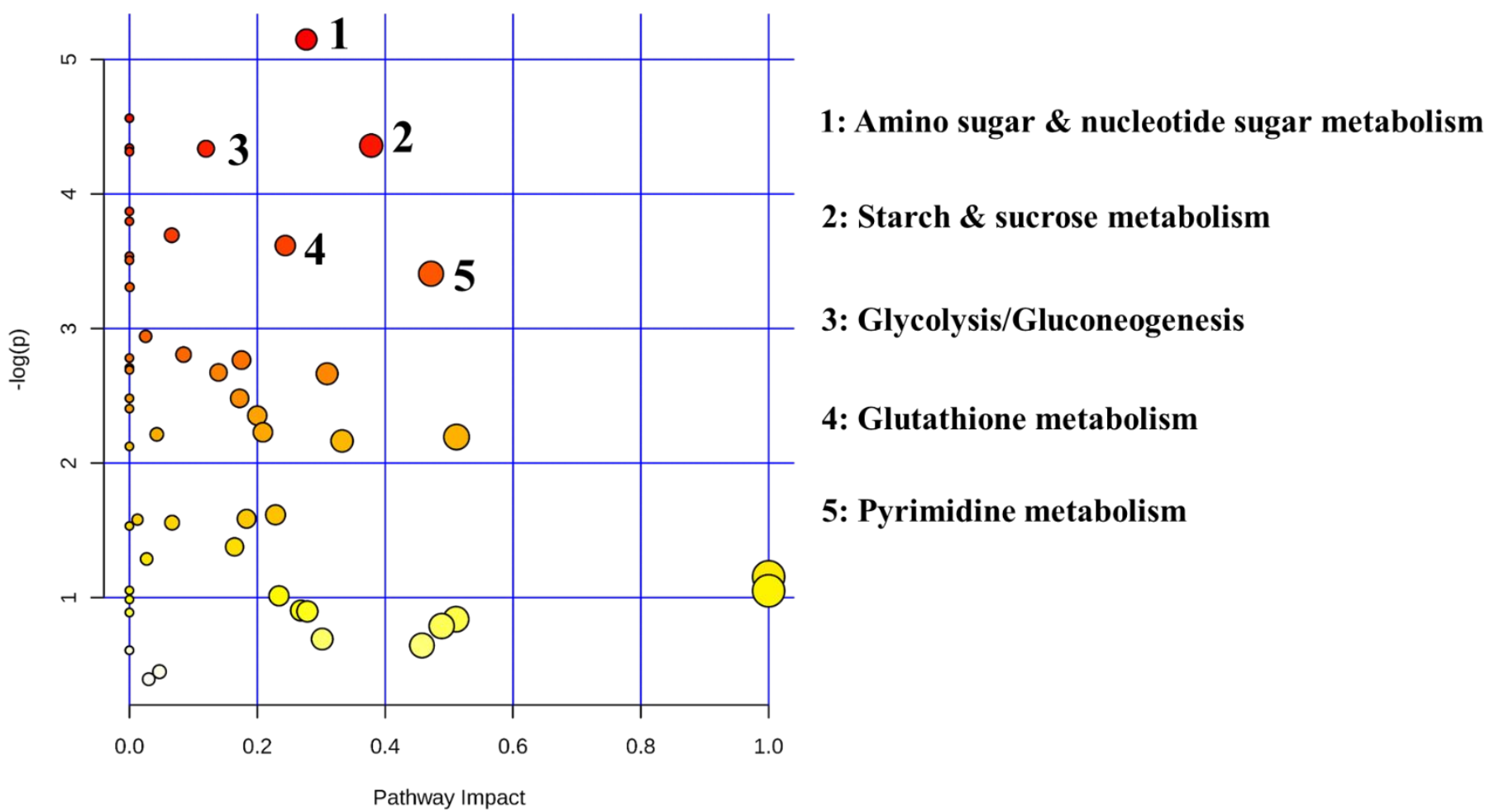

Figure S6. Biological pathways of microorganisms in soil altered by AgNPs exposure. 

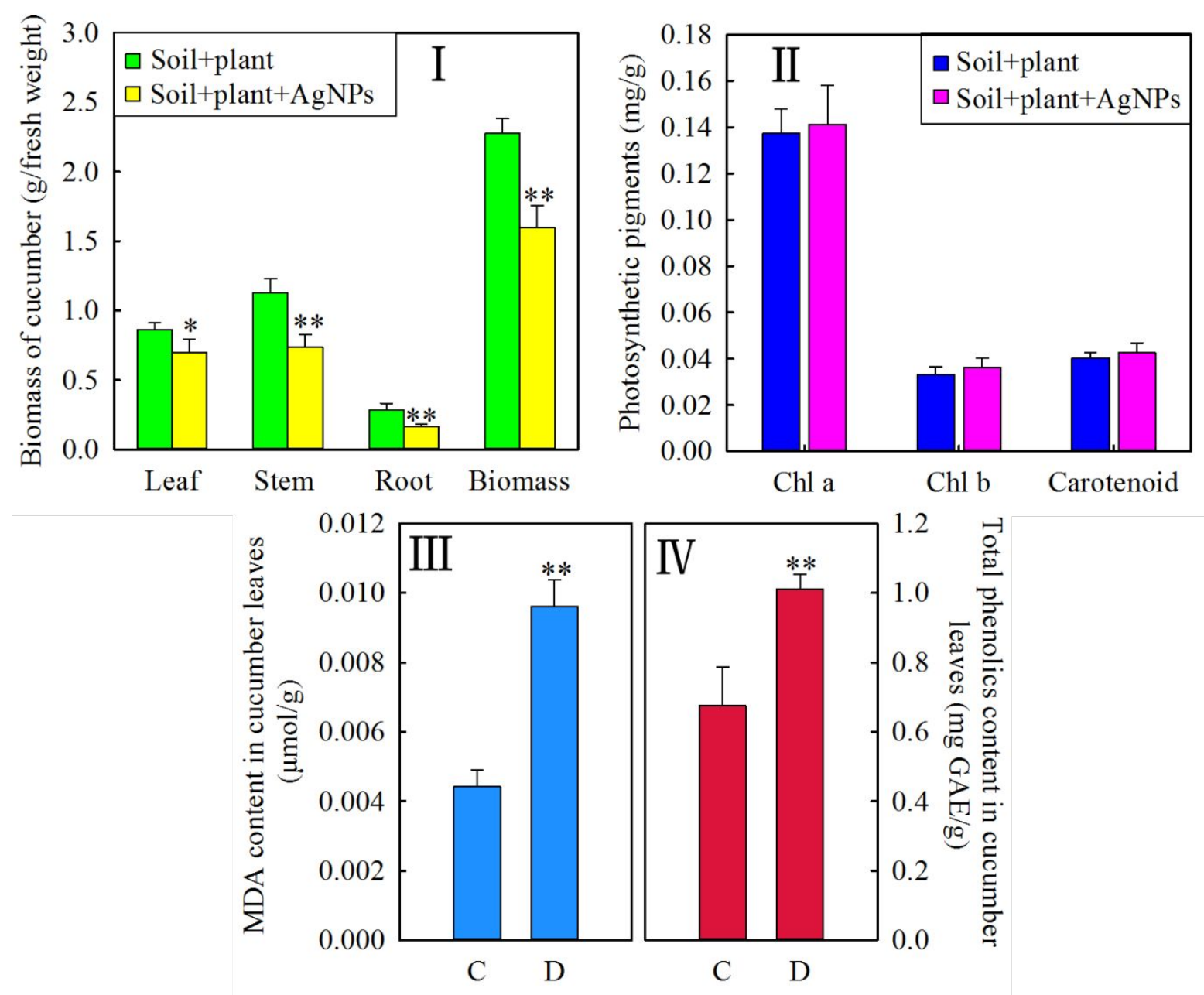

Figure S7. Cucumber fresh biomass (I), photosynthetic pigments (II), MDA content (III) and total phenolics content (IV). C represent "soil+plant", D represent "soil+plant+AgNPs". The data were represented by means \pm SD by four replicates. * represent the significance is below $0.05, * *$ represent the significance is below 0.01 . 